Taxation and slavery: the meia siza

\title{
Tributação e escravidão: o imposto \\ da meia siza sobre o comércio de escravos na província de São Paulo (1809-1850)
}

tax on the internal slave trade in

the province of São Paulo

(1809-1850)

\section{Guilherme Vilela Fernandes}

Aluno de graduação em Ciências Econômicas do Instituto de Economia da Universidade Estadual de Campinas. Desenvolve pesquisa de Iniciação Científica desde Agosto de 2003, com bolsa da FAPESP, sob orientação da Profa Dra. Wilma Peres Costa.

\begin{abstract}
Resumo
Esta pesquisa tem como uma de suas metas analisar a criação e a evolução do imposto Meia Siza sobre o comércio de escravos ladinos na Província de São Paulo, entre 1809 e 1850. Observam-se os esforços do governo na implementação desse imposto, as mudanças ocorridas na legislação geral e provincial, e os debates políticos em torno dele, conferindo destaque aos anos posteriores a 1831, quando o tráfico africano de escravos foi colocado oficialmente fora da lei.
\end{abstract}

\section{Abstract}

The main goal of this study is to analyze the establishment and evolution of the meia siza tax over the trade on brazilian-born (ladinos) slaves in the Province of São Paulo, in between the years of 1809 and 1850. It focuses governmental efforts towards the creation and inforcement of this tax, the changes made on general and provincial laws on this subject and the political debate around it. Special attention has been confered to the period after 1831, when external (african) slave trade was officialy outlawed.

\section{Palavras-chaves}

história econômica, escravidão, sistema fiscal, tráfico negreiro, São Paulo

\section{Keywords}

economic history, slavery, tax system, slave trade, São Paulo 


\section{Apresentação}

0 objetivo deste informe de pesquisa é destacar aspectos centrais desenvolvidos nos relatórios do meu projeto de Iniciação Científica, intitulado "Tributação e Escravidão: o imposto da Meia Siza sobre o comércio de escravos na Província de São Paulo (1809-1850)".

Partindo de leituras e discussões anteriormente feitas no interior da linha de pesquisa desenvolvida pela Profa. Dra. Wilma Peres Costa no Instituto de Economia da Unicamp sobre as relações entre a fiscalidade e o processo de construção do Estado Brasileiro no século XIX, o trabalho transformou-se em Projeto de Iniciação Científica em agosto de 2003, passando a receber financiamento da FAPESP. Desde 2004, ele vem se desenvolvendo no interior do Projeto Temático Fundação do Estado e da Nação - Brasil (c.1750- c. 1850), no sub-projeto Estado e Soberania.

A pesquisa se propõe a reconstituir a trajetória histórica de um dos impostos criados a partir da chegada da Familia Real ao Brasil: o imposto da meia siza (5\%) sobre todas as transações mercantis envolvendo escravos ladinos, isto é, nascidos na América Portuguesa (Alvará de 3 de junho de 1809). Aplicado a todo o território português na América, este imposto foi conservado depois da Independência do Brasil, tendo ficado vigente enquanto durou a escravidão no pais. 0 trabalho procura observar a trajetória desse imposto na Província de São Paulo, entre 1809 e 1850, sendo que, no presente Informe, apresento as discussões relativas a este imposto em âmbito nacional. Compreendendo o período de 1809 à 1850, limitamos o estudo a uma época em que se deu a transição do país da condição de colônia para a de Estado, abrangendo, portanto, as discussões sobre a necessidade de alterações no aparato burocrático-estatal, e as conseqüências dessas ações sobre o referido imposto, observando, que no mesmo periodo dá-se a extinção do tráfico africano de escravos.

Ao incidir sobre o tráfico interno de escravos, a partir do momento em que o tráfico externo se torna ilegal, o estudo da meia siza sobre o comércio de escravos ganha nova importância e repercute no plano politico, econômico e social. Por incidir sobre o comércio interno e sobre o "escravo ladino", a meia siza é uma das únicas formas de taxar o comércio escravo, uma vez que o tráfico externo, tornado ilegal, passava a escapar da arrecadação. Os conflitos em torno desse imposto permitem, assim, investigar vários aspectos da relação entre o escravismo e a construção do Estado: a relação entre comércio legal/ilegal, a relação entre o centro e as províncias, a relação entre o Estado e os proprietários de escravos.

0 estudo procura observar a evolução deste tributo na Província de São Paulo, atentando para as suas implicações econômicas (o comércio interno de escravos) e políticas (seu papel no processo de formação do Estado brasileiro, no que toca a articulação entre o Poder Central e as Provincias), privilegiando o período posterior a 1831, quando as potenciais dificuldades advindas da expiração do prazo acordado com a Inglaterra para o fim do tráfico africano coincidiram com uma forte expansão das atividades agrícolas na província, representadas pela produção de açúcar e, posteriormente, de café.

Além disso, ao nos focarmos na província de São Paulo podemos observar que o tema ganha importância específica, por coincidir o periodo de acirramento das pressões inglesas pelo cumprimento do Tratado que prometia o fim do tráfico externo com o início da expansão da economia 
Joseph A. Schumpeter. The crisis of the tax state. International Economic Papers. Nova York: MacMillan, n.4, 1954.

Charles Tilly. The formation of national states in Western Europe. Princeton, Princeton University Press, 1975.

Wilma Peres Costa. Do Domínio à Nação: os impasses da fiscalidade no processo de Independência in Artigo para o volume referente ao Seminário Identidades Políticas na América Latina.

4

Helen Osório. As elites econômicas e a arrematação dos contratos reais: o exemplo do Rio Grande do Sul (século XVIII). In João Fragoso, Maria Fernanda Bicalho e Maria de Fátima Gouvêa (org). O Antigo Regime nos Trópicos, a dinâmica imperial portuguesa (séculos XVI-XVIII), RJ, Civilização Brasileira, 2001.

\section{5}

Viviane Tessitore. As fontes da riqueza pública, tributos e administração tributária na Província de São Paulo. Tese de mestrado. São Paulo, Universidade de São Paulo, Faculdade de Filosofia, Letras e Ciências Humanas, 1995.

\section{6}

Robert W Slenes. "Grandeza ou Decadência? 0 mercado de escravos e a economia cafeeira da provincia do Rio de Janeiro, 1850-1888". In: Iraci del Nero da Costa (org). Brasil: História Econômica e Demográfica, São Paulo, Instituto de Pesquisas Econômicas, 1986.

Anthony D Smith. La identidad nacional. Trama Editorial, Madrid, 1997. cafeeira na província, que era grande demandante de mão de obra escrava. Assim, as divergências entre as camadas dominantes regionais e o poder central tornam-se mais intensas no periodo e podem ser estudadas através de um tributo que incide diretamente sobre a escravidão.

\section{Exposição do desenvolvimento das atividades de pesquisa}

Desde seu início, em agosto de 2003, a pesquisa fundamentou-se em duas ações complementares: a primeira fixou-se na leitura e discussão de textos referente aos temas relacionados ao desenvolvimento da pesquisa, buscando aprofundar a compreensão do período histórico como um todo, ao mesmo tempo em que se procurava verticalizar os temas referentes ao tratamento histórico da questão fiscal. Esta ação foi efetuada a partir do texto de Joseph Schumpeter, que defendera a importância do estudo da história da fiscalidade para a compreensão da formação do Estado¹. Outras referências importantes para o desenvolvimento dessa ação foram os de Charles Tilly 2 e Wilma Peres Costa ${ }^{3}$. Ainda destaco nesse ponto, importantes sugestões de leituras dos textos debatidos nos seminários realizados pelos pesquisadores ligados ao Projeto Temático e outras referências bibliográficas, como os textos de Helen Osório - As elites econômicas e a arrematação dos contratos reais: o exemplo do Rio Grande do Sul (século XVIII) ${ }^{4}$, de Viviane Tessitore - As fontes da riqueza pública, tributos e administração tributária na Província de São Paulo ${ }^{5}$, de Robert W. Slenes - Grandeza ou Decadência? 0 mercado de escravos e a economia cafeeira da província do Rio de Janeiro, 1850-18886, de Anthony D. Smith - La identidad nacional7 e o debate em torno do texto de Ilmar Rohloff de Mattos Construtores e Herdeiros: a trama dos interesses na construção da unidade politica, realizado através dos textos de Wilma Peres Costa (- O Império do Brasil: dimensões de um enigma) e Cecília Helena de Salles Oliveira (- Heranças Recriadas: especificidades da construção do Império do Brasil), bem como o de Miriam Dolhnikoff - Elites e poder legislativo no Brasil do século XIX.

A segunda ação refere-se à coleta e organização de fontes primárias, objeto central de atenção desta pesquisa, através do acompanhamento da legislação referente a esse imposto, tanto no plano geral quanto no provincial, destacando as principais leis que caracterizaram mudanças na forma de arrecadação. Para tanto, percorremos os volumes da Coleção de Leis do Império do Brasil ( disponiveis para download no site http://www.camara. gov.br), onde há a listagem de leis, alvarás, decretos, cartas régias e decisões dos anos de 1808 até 1851 referentes à escravidão e à fiscalidade. Trabalhamos também com os Relatórios do Ministério da Fazenda (18231850) e os Relatórios dos Presidentes de Província de S. Paulo (1838-1850), por meio do download dos mesmos relatórios do site da Universidade de Chicago http://wwwcrl.uchicago.edu).

Foi também valioso para este trabalho as informações contidas no site da Biblioteca Nacional http://catalogos.bn.br/, oriundos do Projeto Tráfico de Escravos e Escravidão, iniciado pela UNESCO em 1999, no contexto do Programa Memória do Mundo daquela Organização. Parte desse trabalho se faz com a incorporação de instrumentos de pesquisa antigos e novos como os Regulamentos expedidos pelo exmo. Governo Provincial para a execução de diversas leis colligidos e anotados pelo Bacharel José Cândido de Azevedo Marques e mandado imprimir pelo exmo. Sr. Dr. João Theodoro Xavier, presidente da Província de São Paulo 
José Cândido de Azevedo Marques.

Regulamentos expedidos pelo exmo. Governo Provincial para a execução de diversas leis colligidos e anotados pelo Bacharel... e mandado imprimir pelo exmo. Sr. Dr. João Theodoro Xavier, presidente da Província de São Paulo na forma da lei que autorisou a reimpressão da legislação provincial. São Paulo, Typographia do "Correio Paulistano", 1874.

9

Viviane Tessitore. As fontes da riqueza pública, tributos e administração tributária na Província de São Paulo. Tese de mestrado. São Paulo, Universidade de São Paulo, Faculdade de Filosofia, Letras e Ciências Humanas, 1995.

10

Guilherme de Paula Costa Santos. Relatório de Pesquisa de Iniciação Cientifica - $A$ Reorganização do Estado Português na América (1808 - 1815): estudo do acervo do Museu Paulista/USP - PIBIC/CNPQ, 2003.

11

Luis Gonçalves dos Santos (Padre Perereca). Memórias para servir à História do Reino do Brasil, RJ, Livraria Editora Zelio Valverde, 1943, pág. 258-259. na forma da lei que autorisou a reimpressão da legislação provincia/8, a já citada tese de mestrado de Viviane Tessitore ${ }^{9}$ e o Relatório de Pesquisa de Iniciação Científica de Guilherme de Paula Costa Santos ${ }^{10}$.

A partir dessas diversas fontes, pudemos organizar um repertório comentado da legislação fiscal do Império entre 1808 e 1851 (com ênfase nos impostos que se referem à escravidão) com o objetivo de organizar um repertório com a legislação pertinente ao tema da pesquisa, resultando em um instrumento de pesquisa para os demais pesquisadores do grupo Temático. Espera-se que, com o devido tratamento técnico, esse repertório possa ser disponibilizado para outros pesquisadores, através do site do Temático.

\section{Antecedentes: reformulação fiscal e administrativa na metrópole e suas influências sobre o Brasil}

0 ano de 1808 é um referencial na história colonial brasileira, pois o Brasil receberia a presença da Família Real e da Corte portuguesas. Devido ao expansionismo napoleônico, restou à elite dirigente do reino lusitano refugiar-se na sua principal colônia, transferindo para cá parte significativa do aparelho estatal da Metrópole e criando um grande conjunto de novas instituições visando a viabilizar o governo das possessões americanas a partir do Rio de Janeiro. Se a antiga estrutura tributária mantinha-se ilesa, a esta foram somadas novas formas de impostos, com o claro intuito de sustentar o funcionamento do poder real que aqui se instalava. Nesse intuito o Príncipe Regente "(...)tendo em consideração o quanto convém nas precisões urgentes, em que se acha o Estado, [buscou] estabelecer rendimentos que bastem para a despesa pública, pois que não podem suprir os que já se achavam estabelecidos (...)", procurando também "aumentar as rendas públicas, afim de sustentar com decoro a majestade do trono, o esplendor da nova Corte, e muitos estabelecimentos públicos indispensáveis para o bem, e prosperidade nacional (...)".11

Foi criado em 1808 o Erário Régio, nos moldes do Erário de Lisboa, como órgão superior, ao qual estavam subordinadas as Juntas de Administração da Fazenda nas Províncias e suas Estações Arrecadadoras. A cada novo serviço instituído no País correspondia o aumento de tributos existentes ou a criação de novos. Não havia um critério uniforme do sistema fiscal que primasse pela objetividade e abrangência, tratava-se, portanto de uma outra orientação fiscal que não aquela que contemplasse ao retorno em benefícios da população, e sim às necessidades imediatas da Coroa portuguesa e sua manutenção na colônia.

Dom Rodrigo de Souza Coutinho, ministro da Marinha e Ultramar (1795) e Ministro e Secretário de Estado dos Negócios da Guerra e Estrangeiros (1812), a partir de 1809, introduz uma série de taxas que visavam viabilizar a manutenção da própria Corte, que já se encontrava aqui desde 1808, tais como:

I - Direitos aduaneiros de entrada cobrados à razão de $15 \%$ sobre o valor oficial, estabelecido em pauta alfandegária, das mercadorias de procedência portuguesa e inglesa, e de $24 \%$ sobre o valor oficial dos artigos de outras origens, excluidos tanto de uma quanto de outra taxa os vinhos, licores, azeites e vinagres; nas alfândegas eram arrecadados, ainda, os direitos de entrada de escravos e, entre outras contribuições de menor vulto, os direitos de baldeação, os de guarda-costa, os de reexportação e o imposto de ancoragem dos navios estrangeiros; 
12

Deveza, Guilherme - Política tributária no periodo imperial, in Holanda, Sérgio Buarque de (org.) HGCB, S.P., Difusão Européia do Livro, 1985 (4a. ed.), Tomo II, vol. IV, pág. 61-62.

\section{3}

Em 1699 a Coroa criou uma taxa de 1000 réis sobre cada escravo que passasse pela llha de São Tomé para auxiliar a Igreja. Duas décadas mais tarde, com a necessidade de oferecer mais escravos às minas brasileiras, Portugal estabeleceu a Feitoria da Ajuda, na Costa da Mina e, junto com ela, uma nova taxa de 1.000 réis por escravo, destinada à proteção do tráfico africano e prevenção do contrabando ao longo da costa. Outro imposto foi introduzido em 1714-1715, aplicado sobre os escravos que, de Pernambuco, Bahia e Rio de Janeiro, eram destinados a Minas Gerais e também sobre o comércio de escravos nascidos no Brasil. Essa taxa de 4500 réis por cabeça, era destinada a proteger os interesses açucareiros, que temiam que seus suprimentos de escravos novos fosse inteiramente desviados para as minas, mas logo se tornou uma importante fonte de receita para a Coroa. Os escravos que entravam em Minas Gerais, recebiam também um tributo interno, as entradas, taxação estabelecida entre 1710 e 1714 , que incidia sobre todas as mercadorias, animais e veículos que entrassem em Minas Gerais das capitanias adjacentes, e da qual esperava-se pagar boa parte dos custos do governo real em Minas. Ver Dauril Alden. Royal Govenment in Colonial Brazil, with special reference to the Administration of Marquis of Lavradio, Viceroy, 1769-1779, Berkeley and Los Angeles, University of California Press, 1968, pág. 303.
II - Dízimos, em que incorriam os gêneros de cultura e criação de todas as províncias, e para cuja cobrança, antes feita por administração ou por contrato de arrematação, com grave prejuizo e vexame dos contribuintes, o decreto de 16 de abril de 1821 estabeleceu novas regras;

III - Imposto de exportação representado pela taxa de $2 \%$ sobre todos os gêneros não sujeitos a qualquer outro subsídio ou direito de saída;

IV -Décima sobre o rendimento líquido anual dos prédios urbanos, ou sobre o valor do aluguel arbitrado, no caso de neles morarem seus donos;

V - Novo imposto de carne verde constituído pela contribuição de cinco réis em cada arratel de carne fresca de vaca;

VI -Imposto conhecido como "subsídio literário", pois destinava-se ao pagamento dos mestres-escolas, originalmente instituído pela carta régia de 10 de novembro de 1772, e que, no Brasil, corresponderia a um real em cada arratel de carne verde que se cortasse nos açougues, e a dez réis em camada de aguardente da terra; nos termos da carta régia de 25 de agosto de 1805, a contribuição sobre a carne passou a ser de 320 réis sobre cada rês abatida, e a da aguardente, de 10 réis por medida, regulada esta pela camada de Lisboa;

VII -Impostos sobre aguardente de consumo;

VIII-Imposto sobre seges, lojas e embarcações, conhecido também como "Imposto do Banco", pois fora criado por alvará de 20 de outubro de 1812 para, com o seu resultado, constituir-se a cota da Fazenda Real no capital do Banco do Brasil;

IX -Imposto sobre o tabaco de corda, cobrado na base de 400 réis por arroba, de conformidade com o alvará de 28 de maio de 1808;

$X$ - Novos e velhos direitos, que remontavam à antiga legislação portuguesa e de que eram vários os atos regulamentares, direitos esses pagos para o provimento de empregos e de outros títulos expedidos pelas autoridades gerais e provinciais;

$\mathrm{XI}$-Direitos sobre os escravos que se despachavam para as minas, velha contribuição decorrente do alvará de 3 de março de 1770 e que passou a ser cobrada na forma estabelecida pelo decreto de 20 de agosto de 1808;

XII -Imposto do selo do papel e décima das heranças e legados, ambos regulados por alvará de 17 de junho de 1809;

XIII-Contribuições diversas, como taxas dos correios, dízimos de chancelaria, terças de ofícios, direitos de portagem, pedágios, taxas de transito entre as províncias, cobradas, não raro, pelas autoridades locais. ${ }^{12}$

Esse conjunto de impostos foi aplicado à Corte e a todas as Províncias, buscando, pela primeira vez, homogeneizar um sistema que, durante o periodo colonial, fora bastante diferenciado.

\section{Escravidão e fiscalidade: a introdução da meia siza em 1809}

A introdução da meia siza sobre o comércio de escravos ladinos adicionava mais um imposto sobre a escravidão àqueles que estavam em vigência durante todo o período colonial. ${ }^{13}$

0 alvará que criou a meia siza referia-se à necessidade de sua introdução para atender o aumento significativo das despesas do Estado com 
14

Coleção de Leis do Império do Brasil (18081889). Fonte: Site da Câmara dos Deputados, www.camara.gov.br pág. 69,70,71.

\section{5}

Coleção de Leis do Brasil de 1808 - Cartas de Lei, Alvarás, Decretos e Cartas Régias de 1809 site da Câmara dos Deputados: www.camara gov.br, pág. 69, 70, 71 e 72 . a transferência da Corte para o Rio de Janeiro, e às vantagens que apresentava em comparação com outros impostos: "(...) sendo necessario, e forçoso estabelecer novos impostos, para nas urgentes circumstâncias, em que se acha o Estado, poder supprir-se as despezas publicas, que se tem augmentado: não podendo bastar os rendimentos, que haviam, e que eram appropriados a outros tempos, e a mais moderadas precisões: e convindo lançar mão dos que já são conhecidos desde o principio da Monarchia, e que merecem preferencia por menos gravosos, e por terem methodo de arrecadação mais suave, e approvado pela pratica, e experiencia (...) e tendo estas conhecidas vantagens a siza das compras e vendas, maiormente por se pagar em ocasião menos penosa, quando se transfere o domínio".14

D. João VI, pelo alvará de 3 de junho de 1809, introduzia no Brasil a meia siza dos escravos ladinos juntamente com a siza dos bens de raiz. A meia siza consistia numa taxa de 5\% (metade da porcentagem da siza, que era de 10\%) sobre a compra e venda, arrematação e adjudicação de escravos ladinos, ou seja, aqueles que não se compraram de negociantes de escravos, os que já estavam no Brasil. Analisando o mesmo alvará, podemos verificar que embora o Estado projetasse formas de arrecadação distintas para as duas sizas fosse, permitiu-se que elas assumissem, desde o início, o mesmo modelo de arrecadação e os mesmos agentes arrecadadores 15 :

I. De todas as compras, vendas e arrematações de bens de raiz, que se fizerem em todo este Estado e Domínios Ultramarinos, se pagará siza para a minha Real Fazenda, que será de dez por cento do preço da compra, sem que desta contribuição se entenda ser isenta pessoa ou corporação alguma, por mais caracterizada ou privilegiada que seja a que intervier em semelhantes contratos; em conformidade do que se acha estabelecido nos Alvarás de 24 de outubro de 1796 e 8 de julho de 1800.

II. Pagar-se-á também em todo este Estado do Brasil para a minha Real Fazenda meia siza, ou cinco por cento do preço das compras e vendas dos escravos ladinos, que se entenderão todos aqueles que não são havidos por compra feita aos negociantes de negros novos, e que entram pela primeira vez no país, transportados da Costa de África.

III. Para a arrecadação da siza dos bens de raiz proporão as Câmaras três pessoas das mais abonadas que houver, para se escolher uma para Recebedor ou Tesoureiro nesta Corte e Distrito da Capitania do Rio de Janeiro pelo Conselho da minha Real Fazenda, e nas demais Capitanias das Juntas da Administração e Arrecadação dela; por maneira que haja uma em cada Cidade e Vila, em que houver Câmaras; e os Oficiais delas ficarão e os seus herdeiros responsáveis pelas faltas das pessoas, que propuzerem e que forem aprovadas.

IV. Os Recebedores nomeados receberão as sizas que thes forem as partes pagar, carregando-Ihas em receita os Escrivães das Câmaras, que hei por bem que sirvam de Escrivães das sizas, sendo Juizes delas os mesmos Juizes de Fora, onde os houver, e os Ordinários em cada uma das Vilas respectivas. Para esta carga haverá um livro rubricado pelos Ouvidores das Comarcas, nas Vilas em que forem Juizes das sizas os Ordinários, e nas demais pelos mesmos Juizes de Fora; e perceberão, o Escrivão um por cento pelo feitio e escrituração das certidões, e o Tesoureiro também um por cento pela guarda do dinheiro, sem mais ordenado ou emolumento algum. 
V. No fim de cada três meses, e nos primeiros oito dias seguintes, se remeterá ao meu Real Erário o que se tiver arrecadado nesta Corte e Província, com o competente conhecimento extraído do respectivo livro assinado pelo Juiz, Recebedor, e Escrivão, dando-se a necessária quitação para ressalva do referido Recebedor com as clarezas precisas. Nas Capitanias deste Estado e dos Domínios Ultramarinos se fará a remessa às Juntas da Administração e Arrecadação da minha Real Fazenda, por onde se expedirá também a respectiva quitação.

VI. A meia siza, que se deve pagar na venda dos escravos ladinos, se arrendará a quem mais der, fazendo-se as arrematações na forma dos mais Contratos nesta Corte e Província, no Conselho da minha Real Fazenda, e nas referidas Capitanias nas Juntas da Administração e Arrecadação dela.

VII. Enquanto porém se não arrematam, ou por não ser o tempo próprio e oportuno, ou por parecer conveniente administrar por algum tempo para se regular melhor o preço das arrematações, arrecadar-se-á pelo mesmo Recebedor das sizas dos bens de raiz da mesma forma acima prescrita, havendo porém diverso livro em que se lancem as verbas pelo mesmo Escrivão, especificando-se o dia, mês e ano, os nomes dos vendedores e compradores, o nome e a nação do escravo, e o preço da venda, para dele se extrair o conhecimento que deve acompanhar as remessas e as competentes certidões que se devem dar às partes quando as vendas se fizerem por escritura pública. Quando porém forem feitas por escritos particulares, neles declarará o Escrivão das sizas, que foi paga a daquela venda, e que fica em carga ao Recebedor, assinando ambos esta declaração e conservando-se em mão do comprador o título da compra; o apresentará quando Ihe for exigido, incorrendo nas penas deste Alvará quando o não mostrar com a competente verba.

Sendo, em ambos os casos, taxas que incidiam sobre transações mercantis, as sizas tinham como principal punição pela sonegação ou fraude, a nulidade das vendas efetuadas.

VIII. Todas as compras e vendas de bens de raiz, de que se não houver pago a respectiva siza, serão nulas e de nenhum efeito e vigor, e as próprias partes contratantes, ou seus herdeiros poderão desfazê-las em qualquer tempo, e os Escrivães ou Tabeliães que fizerem as escrituras sem certidão do pagamento da siza, com as clausulas determinadas no cap. 20 do Regimento dos encabeçamentos das sizas, e do $\S$ 14 da Ord. Liv. I tit. 78 incorrerão na pena do perdimento do Ofício, na forma da mesma Lei e Regimento.

IX. Na mesma pena de nulidade incorrerão as vendas dos escravos ladinos que se fierem sem o pagamento da meia siza, e serão além disto multados os vendedores e compradores em igual parte na perda do valor do escravo, sendo a metade para o denunciante, se o houver, e a outra, ou toda, não o havendo, para a minha Real Fazenda.

\section{Política tributária do Primeiro Reinado: continuidades, desorgani-} zação e reformas

A especificidade do nosso processo de Independência e a continuidade dinástica que o particularizou não deve encobrir o fato de que, ao mesmo tempo em que havia uma concentração do poder, que fundamentava a 
16

Maria Odila da Silva Dias "A interiorização da metrópole (1808-1853)". In MOTA, Carlos Guilherme (org.). 1822: Dimensões, S.P., Ed. Perspectiva, 1972, pág. 160-84

17

Savério Mandêtta. Impostos, taxas e contribuições: resenha histórica do regime fiscal no Brasil. São Paulo, Colibras, s.d., pág. 529;

18

Guilherme Deveza. "Política tributária no período imperial". In Holanda, Sérgio Buarque de (org.). História Geral da Civilização Brasileira, S.P., Difusão Européia do Livro, 1985 (4a. ed.), Tomo II, vol. IV, pág. 60.

19

Brasil, Ministério da Fazenda, Ministro Manoel Jacinto Nogueira da Gama, Exposição do Estado da Fazenda Pública, do Anno de 1821 à 1823 (publicado em 1823). Inclui orçamento para os annos de 1823, 1824 e 1825. formação do Estado Monárquico, forças de resistência articulavam-se a fim de resistir à ação extrativa do novo núcleo político, procurando conservar autonomias que eram ameaçadas pelo projeto de monarquia unitária e de continuidade dinástica. Se as continuidades dinástica e tributária do periodo colonial foram caracteristicas notáveis na formação do Estado brasileiro, não menos importantes foram as densas origens do autonomismo provincial deixadas pelo passado colonial e que iriam resistir a um processo de construção estatal que tendia a se apresentar como interiorização da metrópole ${ }^{16}$.

A condição econômica herdada era a da economia mercantil escravista, voltada para o mercado internacional e dotada de pouco dinamismo no sentido do mercado interno e da vida urbana, limitando excessivamente a capacidade arrecadadora do Estado. D. João VI e a Côrte, ao saírem do Brasil, contribuiram para elevar o grau da crise financeira brasileira deixando o Tesouro público em péssimas condições, agravado ainda mais pela ocasião de terem retirado grande quantidade de ouro e prata. E D.Pedro, frente à situação deficitária com que deparara após a partida do pai, expõe em carta escrita a este o estado crítico da ocasião: "De parte nenhuma vem nada; todos os estabelecimentos e repartições ficaram; os que comem da Nação são sem número; o numerário do Tesouro é só das rendas da província (do Rio de Janeiro) e estas mesmas são pagas em papel. É necessário pagar tudo quanto ficou estabelecido, como são: o estado maior, tribunais, etc. não há dinheiro como ficou exposto: não sei o que hei de fazer. Haja por bem dar-me um quase repentino remédio, para que eu me não veja envergonhado depois de me ter sacrificado a ficar no meio de ruínas." 17

Pode-se dizer que o momento da Independência do país relacionavase com um desejado rompimento inclusive com os excessos fiscais que vinham da Coroa, observado no Manifesto do Príncipe Regente do Reino do Brasil aos Governos e Nações Amigas, em 6 de Agosto de 1822, em que 0 D. Pedro afirma que Portugal queria "que os brasileiros pagassem até o ar que respiravam e a terra que pisavam". Em outro manifesto, pronunciado ao próprio povo brasileiro, no dia $1^{\circ}$ de agosto também de 1822, D. Pedro garantia aos brasileiros a promessa de que estes teriam um sistema de impostos que respeitaria "os suores da agricultura, os trabalhos da indústria, os perigos da navegação e a liberdade do comércio", facilitando "o emprego e a circulação dos cabedais", desvendando "o escuro labirinto das finanças", que não permitia ao cidadão "lobrigar o rasto do emprego que se dava às rendas da Nação" 18 .

Porém, durante todo o Primeiro Reinado, do ponto de vista tributário, nada fora feito: os mesmos impostos, criados no período colonial, continuaram a ser cobrados. Assim, podemos observar que permaneceu a má distribuição dos tributos, desigual e injusta tributação entre gêneros e problemas na avaliação do montante arrecadado. Inúmeros são os exemplos que caracterizam esta situação: "Se as de mais Provincias deste Reino continuassem a remetter como d'antes para o Thesouro as sobras das suas rendas, sem maior inconveniente de desfalque da renda ordinária, se poderia estabelecer huma consignação mensal, que contentasse a estes Credores; mas actualmente não temos estas sobras, nem sabemos quando poderemos contar com ellas (...)."19 Ou ainda: " (...) as relações das Entradas nos differentes Cofres ds Provincias, (...) estão longe de fornecer os Conhecimentos necessários para com certeza, ou ao menos com razoada apro- 
20

Brasil, Ministério da Fazenda, Ministro Manoel Jacinto Nogueira da Gama, Relatório... em fim do ano de 1825, com o orçamento da renda, e despeza que poderá ter lugar no corrente anno de 1826 (publicado em 1826).

21

Guilherme Deveza. "Politica tributária no período imperial". In Holanda, Sérgio Buarque de (org.). História Geral da Civilização Brasileira S.P., Difusão Européia do Livro, 1985 (4a. ed.), Tomo II, vol. IV, pág. 65. ximação se determinar qual seja a Renda ordinária da Nação em todo o Império; e o mesmo acontece pelo que respeita a sua Despeza. (...) todavia não pode a Commissao informar a esta Camara qual seja o anno a que este quadro se refere; pois que sendo o processo seguido neste trabalho o somar-se as entradas dos Cofres das diversas Provincias constantes de Balanços de epocas diversas, e desencontradas; he elle antes huma amalgama desses mesmos Balanços, do que a demonstração exacta do estado actual da correnteza da Receita, e Despeza do Thesouro".20

Ainda que o governo tomasse medidas, com a finalidade de melhorar a arrecadação e fiscalização dos tributos, carecia a elas uma sistematização, resultando nos esbanjamentos e extravios a que se referia D. Pedro I, na fala com que abriu a Assembléia Geral de 3 de maio de 1827. E o passo inicial para "um sistema de finanças bem organizado", que o Imperador reclamava, foi a votação da primeira lei de orçamento de 14 de novembro do mesmo ano, a qual, embora se referisse apenas ao Tesouro Público na Corte e Província do Rio de Janeiro, não deixava de traçar algumas normas em relação à receita e despesa das demais províncias. ${ }^{21}$

Portanto, a Fazenda necessitava de mudanças urgentes, dotando-a de instrumentos que atuassem ativamente nas Províncias e uma arrecadação mais eficiente. É na Regência que os esforços de implantação dessas metas foram bem sucedidos.

\section{Regência e Segundo Reinado: a extinção do tráfico}

Embora houvera uma forte oposição da diplomacia britânica à manutenção do tráfico negreiro (que veio a ameaçar a própria soberania do Estado brasileiro), foi de suma importância a manutenção e a expansão da produção agrário-exportadora via trabalho compulsório para atenuar o endividamento com a própria Inglaterra, motivo forte o suficiente para o centro se impor sobre os poderes provinciais.

Através da análise da legislação geral, com a criação, extinção ou alteração de diversos impostos observamos as deficiências do aparato fiscal do Brasil recém-independente, sendo que a reorganização fazendária do Brasil deu-se através da Lei de 4 de Outubro de 1831, criando o Tribunal do Tesouro Público Nacional, como órgão central, e as Tesourarias das províncias, como órgãos descentralizados. E assim inicia-se um processo de unificação e articulação das repartições fazendárias. Extingue-se o Erário Real (Tesouro Público) e o Conselho da Fazenda. Assim, o período que vai da abdicação de D. Pedro I até a proclamação da maioridade de D. Pedro II, representa para o setor administrativo um passo fundamental na mudança do regime fiscal.

0 aumento da autonomia provincial viria em 1834, com o Ato Adicional, definindo a competência das Assembléias Legislativas Provinciais sobre a estipulação das despesas municipais e provinciais, e os impostos que eram necessários para cada província, desde que não prejudicassem as imposições gerais do Estado, não legislando sobre impostos de importação (a maior receita do governo central e motivo de discussões entre ele e as províncias). Dessa forma, observamos como a meia siza, originalmente um imposto de caráter geral, transfere-se para a esfera provincial (exceto no município do Rio de Janeiro).

Além disso, o fato de que o tráfico africano de escravos se tornava oficialmente ilegal (apesar de ser praticado em grande quantidade), fazia com que a meia siza fosse o único imposto sobre o comércio de 
22

Brasil, Ministério da Fazenda, Ministro Bernardo Pereira de Vasconcellos, Relatorio... do Anno de 1831, pág. 66 e 67.
23

Brasil, Ministério da Fazenda, Ministro Bernardo Pereira de Vasconcellos, Relatorio... do Anno de 1831, pág. 68-69.

24

Brasil, Ministério da Fazenda, Ministro (Manoel do Nascimento Castro e Silva) Proposta e Relatório... do anno de 1835 apresentados na Assembléia Geral Legislativa na Sessão Ordinária de 1836. (Publicado em 1836), pág 51.

25

Brasil, Ministério da Fazenda, Ministro Miguel Calmon du Pin e Almeida, Proposta e Relatorio.. do Anno de 1840 apresentados na Assembléia Geral Legislativa na Sessão Ordinaria de 1841 (publicado em 1841) pág. 28-29. escravos que poderia ser cobrado pelo governo, pois incidia sobre os escravos ladinos (isto é, nascidos no Brasil, e não trazidos da África). Os governos regenciais não queriam, porém, ferir os interesses dos grandes fazendeiros e proprietários de escravos, como mostra Bernardo Pereira de Vasconcellos: Permiti-me, senhores que vos apresente as minhas reflexões sobre alguns dos impostos atuais. A meia Siza dos escravos é um imposto oneroso, ele afeta a classe menos abundante e afeta os capitais, dois vícios consideráveis em todo o gênero de imposições, além de ser um veículo de fraudes, e de imoralidades. (...) Vasto é o campo para reflexões, mas contentando-me de despertar sobre estes a vossa atenção, estou certo que dareis um ajuizado golpe de vista a todos os outros. Em geral o nosso sistema de impostos é consideravelmente vicioso, constando de uma multidão de minuciosas taxas trazidas de Portugal nos malfadados tempos coloniais, ou lançadas aqui sem conhecimentos dos princípios da Ciência, quando aparecia ou se fingia aparecer necessidade de aumento de renda"22

As autoridades da época afirmavam que a dificuldade da tributação não vinha do fraco desenvolvimento das atividades econômicas, pois segundo o Ministro Bernardo Pereira de Vasconcellos, devia-se "muito mais atribuir ás dificuldades, que sofre a sua cobrança do que à falta de meios dos contribuintes (...) Daqui se colhe que o atual método da percepção é insuficiente e inútil, e por conseqüência necessário recorrer a um outro mais eficaz e que impeça o desaparecimento dos dinheiros públicos nas mãos dos encarregados de sua cobrança, ou as fraudes usadas pelos contribuintes para evadir-se do pagamento. O governo, é verdade que já tem dado as providências, que vos refere na Segunda parte do relatório, mas não posso deixar de, confessar-vos que elas melhoraram um pouco o estado desgraçado em que se achava a arrecadação e fiscalização da renda, mas não curaram os defeitos, que vem da sua origem: erro é e será sempre querer edificar sobre alicerces que por toda parte tombam em ruina." 23

Desde então, o imposto da meia siza passou a ser constantemente citado como problemático, no que tange à forma de arrecadação, e sujeitos à constante sonegação ${ }^{24}$ :

"A Meia Siza dos escravos reclama adequada providencia, a fim de que seu rendimento não se torne nullo pelo defraudamento e constantes dollos que se commettem, sem que na Lei da sua creação se possa achar meio de evitar-se o prejuizo da Fazenda pela impraticabilidade daquelles que ella estatuio, quaes os de denuncia, que nunca se promove, e la meu ver) impolitico, e repugnante com o caracter Nacional: a medida proposta no meu anterior Relatório poderia obstar à continuação de semelhante desmoralisação."

Em 1840, Miguel Calmon Du Pin e Almeida conclui que as medidas existentes de combate à sonegação não tiveram êxito no objetivo de restringir as fraudes: 25

"São igualmente mal arrecadadas, a meia sisa dos escravos (...). Pelo que pertence à Receita Geral, o Novo Imposto de 50\% de reexportação da pólvora para a Costa da África, estabelecido pelo art. $9^{\circ}$ da Lei de 20 de outubro de 1838 como repressivo do tráfico illicito, tem somente produzido o effeito de privar o Thesouro de uma Renda annual de 30000\$, a que subia a mesma exportação quando sujeita a $15 \%$, sem todavia por 


\section{6}

Discurso recitado pelo exmo. presidente, Miguel de Souza Mello e Alvim, no dia 7 de janeiro de 1842 por occasião da abertura da Assembléa Legislativa da provincia de S. Paulo. S. Paulo, Typ. Imparcial de Silva Sobral, 1842, pág. 20. Site: http://wwwcrl.uchicago.edu. Ver também Brasil, Ministério da Fazenda, Joaquim Francisco Vianna, Proposta e Relatorio... do Anno de 1842 apresentados na Assembléia Geral Legislativa na Segunda Sessão da $5^{a}$ Legislatura (publicado em 1843), p. 32

27

Idem estorvos a um tráfico que infelizmente acha sobejo alimento na polvora navegada para a África de muitos portos da Europa e America. Está verificado que depois de 1 de janeiro de 1839, dia em que começou a cobrança desse imposto, nenhum despacho de reexportação de polvora se effetuou para a Africa e que não só temos perdido a Renda acima notada, como a vantagem que resultaria da importação da polvora necessaria para o commércio licito, a que só tem posto estorvos a elevação do imposto. Parece por tanto conveniente restabelecer a antiga imposição de 15\%".

Embora essas medidas, num primeiro momento tiveram algum sucesso, a sonegação continuaria muito forte, visto que o problema se encontrava no momento de declarar a origem, nação, idade, sinais pessoais dos escravos, o nome do comprador, do escravo, o dia, mês e ano em que se efetuou a venda, ou seja, procedimentos que poderiam ser denunciadores do tráfico ilícito, que sendo feitos através de negociações particulares não havia modos de controlar. Miguel de Souza Mello e Alvim, presidente da província de São Paulo em 1842, relata este problema: "É cada vez maior o extravio do imposto da meia siza da venda d' escravos, pois que a administração não tem um meio directo, nem indirecto de obstar a defraudação que d'elle se faz, na maior parte da Província. Hoje só paga este imposto quem quer; pois as denuncias são cada vez mais raras, e mesmo perigosas, e só apparecem algumas quando o denunciante tem alguma vantagem a tirar".26 E a seguir, declara as razões para tais fraudes: "Atribuo este mal a faculdade que dão nossas Leis de fazerem-se as vendas d'escravos por escriptos particulares, que sempre ficão em segredo entre os interessados; por isso se fosse possivel determinar que fossem nullos os contractos de venda d'escravos não reduzidos a escriptura publica, muito se facilitaria a arrecadação d'este imposto, que, a não ser tão defraudado como é, produziria uma renda muito considerável.

As providencias que tendes dado a este respeito só podem ser úteis quando a defraudação consiste no preço da venda; mas como hoje ellas são occultas, não podem produzir o desejado effeito. Vossa illustração proverá de remédio adequado este inconveniente, tão fatal para a arrecadação das rendas, e ao mesmo tempo para a moralidade pública".27

A principal providência que veio a ser tomada pelo Ministro foi 0 esforço de instituir uma matrícula geral de escravos em todas as cidades e vilas do país, como forma de viabilizar a arrecadação da meia-siza.

Assim, observamos como se deu a concordância, a partir do Segundo Reinado, entre partes visivelmente conflitantes: o Estado, e a defesa de uma estrutura fisco-administrativo e os proprietários de escravos, elite econômica do pais, buscando solucionar a problemática de arrecadação da meia siza sobre o comércio de escravos. Eliminando-se os procedimentos fundamentais que caracterizavam os escravos como sendo oriundos do tráfico ilegal (como as declarações de origem, nação, idade, características pessoais dos escravos, o nome do comprador, do escravo, o dia, mês e ano em que se efetuou a venda), os proprietários de escravos obtinham uma documentação que tornava lícita a propriedade sobre os escravos, eliminando suas dívidas com o fisco. E assim o escravo estava novamente sujeito a ser uma mercadoria tributável em todo o território.

Isso persiste por todo o tempo em que durou a escravidão, até 1888, com a abolição da mesma, a 13 de maio, suprimindo também a dívida ativa de todos os impostos referentes a escravos, dada a resistência e até mesmo à impossibilidade financeira de alguns contribuintes em pagá-las. 


\section{Ações futuras da pesquisa}

Pretendemos produzir um repertório contendo minuciosamente a legislação sobre a fiscalidade e a escravidão no plano provincial e continuar a compilação das leis gerais, relacionando a evolução fiscal, decorrentes das transformações ocorridas na legislação referente à escravidão e ao fisco, no plano geral e provincial, observando mais facilmente as contradições entre a legislação geral e aquela que foi posta em prática nas províncias (no caso, São Paulo). Ampliaremos as fontes estudadas, analisando os Relatórios dos Ministérios da Justiça e Agricultura de anos posteriores a 1850, buscando informações sobre o periodo anterior a esta data, visto que, pelo que constatamos, as informações sobre os valores dos impostos arrecadados em cada província eram repassadas (apesar do esforço de uniformização e agilidade do sistema) com um periodo de atraso, ou muitas vezes nem eram enviadas (constituindo uma das principais reclamações dos Ministros). Vale lembrar a importância dessa análise, pois um dos temas predominantes nos Relatórios do Ministério da Agricultura era o tráfico de escravos. 